Encyclopedia of Adolescence 

Roger J. R. Levesque Editor

\section{Encyclopedia of Adolescence}

Second Edition

With 59 Figures and 84 Tables

第 Springer 


\section{Editor}

Roger J. R. Levesque

Indiana University

Bloomington, IN, USA

ISBN 978-3-319-33227-7

ISBN 978-3-319-33228-4 (eBook)

ISBN 978-3-319-33390-8 (print and electronic bundle)

https://doi.org/10.1007/978-3-319-33228-4

Library of Congress Control Number: 2017956138

1st edition: (C) Springer Science+Business Media, LLC 2011

(C) Springer International Publishing AG 2018

This work is subject to copyright. All rights are reserved by the Publisher, whether the whole or part of the material is concerned, specifically the rights of translation, reprinting, reuse of illustrations, recitation, broadcasting, reproduction on microfilms or in any other physical way, and transmission or information storage and retrieval, electronic adaptation, computer software, or by similar or dissimilar methodology now known or hereafter developed.

The use of general descriptive names, registered names, trademarks, service marks, etc. in this publication does not imply, even in the absence of a specific statement, that such names are exempt from the relevant protective laws and regulations and therefore free for general use.

The publisher, the authors and the editors are safe to assume that the advice and information in this book are believed to be true and accurate at the date of publication. Neither the publisher nor the authors or the editors give a warranty, express or implied, with respect to the material contained herein or for any errors or omissions that may have been made. The publisher remains neutral with regard to jurisdictional claims in published maps and institutional affiliations.

Printed on acid-free paper

This Springer imprint is published by Springer Nature

The registered company is Springer International Publishing AG

The registered company address is: Gewerbestrasse 11, 6330 Cham, Switzerland 


\section{Preface to Second Edition}

Like this encyclopedia's first edition, this one responds to the incredibly rapidly growing research on adolescence. That growth comes from many directions. Research on adolescence comes from not only developmental science but also criminology, medicine, public health, sociology, and many disciplines within psychological science as well as research focusing on social institutions dealing with youth, such as child welfare, educational and justice systems. No discipline owns the study of adolescence, a reality that creates a compelling need for this compendium.

Given the nature of the study of adolescence, this edition continues the effort to reach its broad, multidisciplinary audience by providing cutting-edge analyses of what researchers know (and do not know) about adolescent development. As such, the entries center on distinct developmental dimensions of the period of adolescence as well as on how adolescence relates to other developmental periods. As with the first edition, this one draws from four major areas of research: "self, identity, and development in adolescence," "adolescents' social and personal relationships," "adolescents in social institutions," and "adolescent mental health." In doing so, this edition continues to push and create new boundaries shaping our understanding of adolescents and their place in society.

Reflecting the field's dramatic growth, the new edition integrates more than 350 new or updated entries into the original group that contained well over 700 entries. Given the nature of research relating to those topics, the entries necessarily vary in length. Shorter entries provide readers with what we know about emerging topics. For more established areas of research, longer entries give readers more comprehensive analyses written by researchers who have published on the topics. Put another way, when areas of study have expert researchers who have studied the topics and produced substantial research, experts review that research (often their own) and offer what they deem important and worth further study. The point is of significance - leading experts on specific topics wrote the majority of entries, a high number that is a testament to the field's dramatic growth, expansive reach, and need for readily accessible documentation.

A massive undertaking like this one does not come to life without the contributions of literally hundreds upon hundreds of researchers and dozens of support staff. Unlike the first edition, this one particularly benefited from the contributions of several undergraduate assistants, particularly those of Jordan 
Lenchitz. Working with such gifted students, authors and support staff affirmed my belief that the future of research relating to adolescence is in good hands and made me grateful for the opportunity to take stock of current research that lays a foundation for that promising future.

Bloomington, Indiana

Roger J. R. Levesque

November 2017 


\section{Preface to First Edition}

On behalf of my fellow advisory board members, authors, and the reference publishing staff at Springer, I welcome you to the Encyclopedia of Adolescence.

This comprehensive, five volume reference features more than 700 substantive essays covering a broad spectrum of topics central to our understanding of the adolescent period. The majority of these essays are authored by established researchers who have published empirical work and commentaries specifically on their essays' topics. In addition to these essays, the volumes contain shorter essays that provide analyses of key terms, concepts, theories, and legal doctrines that relate to the current empirical understanding of adolescence. Together, these essays are meant to provide readers with a broad sense of research relating to adolescence. They also are meant to highlight important social and policy issues needed to understand more fully the period of adolescence and its peculiar place in society.

The complexity of adolescent life, as well as the diverse and numerous disciplines seeking to understand it, certainly challenges efforts to create a succinct yet comprehensive compendium. The broad diversity of topics and their relationships make it difficult to do justice to topics while, at the same time, not repeat materials in other essays. In response to these challenges and difficulties, the essays' topics were developed by envisioning four major groups of topics. Given the topics' centrality to this project, it is worth highlighting their nature and general content.

The first group deals with the self, identity and development in adolescence. This cluster of essays covers research relating to identity (from early adolescence through emerging adulthood), basic aspects of development (biological, cognitive, social, etc.), as well as foundational developmental theories. In addition, this group of essays focuses on various components of identity, such as those relating to gender, sexual, civic, moral, racial, spiritual, and religious aspects of individuals' social and psychological sense of who they are.

Essays relating to adolescents'social and personal relationships constitute the second group of topics. Essays within this broad area of research focus on the nature and influence of a variety of important relationships. The essays focus, for example, on families, peers, friends, sexual and romantic partners as well as significant nonparental adults. 
The third cluster of topics centers on adolescents in social institutions. Essays in this category address the influence and nature of important institutions that serve as the socializing contexts for adolescents. These major institutions include schools, religious groups, justice systems, medical and other therapeutic contexts, cultural contexts, media, economic statuses, social services and youth organizations.

The fourth and final cluster of topics involves adolescent psychopathology and mental health. This group of topics focuses on the wide variety of human thoughts, feelings and behaviors relating to mental health, from psychopathology to thriving. Major topic examples in this group include deviance, violence, crime, delinquency, pathology (DSM), normalcy, risk, victimization and positive youth development.

The ability to categorize hundreds of topics into reasonably distinct groups proved considerably useful. Most notably, it helped avoid being overwhelmed by the enormity of the task, as several hundred potential topics were culled from journals, books, and a variety of other sources that report on the adolescent period (e.g., media outlets, government reports, and professional association's mission statements and resources). By identifying and assisting in sorting topics, the approach produced the most systematic and comprehensive compendium of empirical findings relating to the period of adolescence. Purposefully included among these topics are some that have yet to be explored empirically as much as might have been expected. Those less explored topics are presented to offer researchers areas in need of further study, highlight important research gaps, and provide an authoritative view of the extent to which current research supports images and views of adolescents. It is hoped that the depth and breadth of this endeavor will serve well students, educators, researchers and practitioners seeking authoritative information about the period of adolescence, in terms of what we know, do not know, and should know.

Bloomington, Indiana

Editor-in-Chief

Roger J. R. Levesque, J.D., Ph.D. 


\section{List of Topics}

Abandonment

Abnormality

Abortion Counseling

Abortion Rights

Abstention

Abstinence

Abstinence Education

Academic Achievement: Contextual Influences

Academic Self-Efficacy

Acculturation

Achievement Motivation

Achievement Tests

Acting Out

Activism

Acute Brain Disorders

Adaptation

Addiction

Adjudicative Competence

Adjustment

Adjustment Disorder

Adolescent Crisis

Adolescent Stress and Coping in the Context of

Poverty

Adolescent Turmoil

Adoption

Adoption and Safe Families Act

Adrenarche

Advertising: Do Not Buy That

Affirmation

Affirmative Action

Affluent Youth

African American Children in Kinship Care

Age of Consent, Majority, and License
Agency

Aggression

Agreeableness

Aid to Families with Dependent Children

Alcohol Use

Alcohol Use Disorders

Alcoholics Anonymous

Alternative Schools

Altruism

Amicus Brief

Amusement Sites and Adolescents' Rights

Anger

Animal Cruelty by Juveniles

Antisocial Personality Disorder

Anxiety Disorders

Anxiety Sensitivity

Appeal

Apprenticeships

Arranged Marriage

Art Therapy

Asperger Syndrome

Assault

Assimilation

Assimilative Psychodynamic Psychotherapy

Assortative Mating

Athletic Programs and Title IX

Attachment During Adolescence

Attention Deficit Hyperactivity Disorder (ADHD)

Authenticity in Relationships

Autism

Autism Spectrum Disorders

Auto Theft

Autonomy and Its Assessment 
Babysitting

Bail

Bariatric Surgery

Battered Child Syndrome

Belief in a Just World

Bereavement

Best Friends

Best Interests of the Child

Betrayal

Bicultural Stress

Bilingual Education Programming

Bilingual Education Rights

Bill of Rights

Binge and Loss of Control Eating During Adolescence

Binge Drinking

Bioethics

Bipolar Disorder

Birth Control

Bisexuality

Blindness and Visual Impairment

Boarding Schools

Body Image

Body Image Assessments

Boot Camps

Borderline Personality Disorder

Boredom

Brain Maturation

Bullying and School Violence Interventions

Bullying Risks and Consequences

Burdens of Proof in Juvenile Courts

Bystander Action

Caffeine Intoxication

Caffeine Use

Callous-Unemotional Traits

Cancer

Cerebellum

Cerebral Cortex

Cerebrum

Cheating

Cheerleading

Child Abuse Prevention and Treatment Act

Child and Adolescent Labor

Child Neglect

Child Savers

Child Sexual Abuse

Child Trafficking for Household Labor
Child Victims' and Child Witnesses' Rights Act

Choking Games

Chronic Disabilities

Circadian Clock

Citizenship Requirements

Civic and Citizenship Attitudes

Civic Involvement

Civil Society

Class Size

Cliques

Coaches

Cocaine Use

Cognitive Behavior Therapy

Cognitive Developmental Components in Treatment

Cohesive Self

Comics

Coming out as Lesbian, Gay, Bisexual, and Transgender

Coming Out Process

Commodification

Community Engagement

Community Organizing

Community Violence

Comorbidity of Psychiatric Disorders

Competitiveness

Complementary and Integrative Health

Compliance

Compulsions

Compulsive Buying

Compulsory Heterosexuality

Condom Use

Confabulation

Confidants

Confidentiality in Law

Conscience

Conscientiousness

Consultation

Contemplation

Content Analysis

Contract Rights

Co-offending

Cool Youth

Co-parenting Conflict

Core Competencies

Corporal Punishment in Schools

Cosmetic Surgery 
Cost-Benefit Analysis

Counsel Rights

Creation Science

Creativity

Criminal Intent

Criminal Responsibility

Critical Consciousness

Crowds

Cults

Cultural Biases in Research

Cultural Sensitivity

Curfews

Custodial Interrogations

Custody

Cyber Aggression

Cyberspace Safety

Dance

Dangerousness

Date Rape

Dating Abuse: Prevalence, Consequences, and Predictors

Dating Abuse: Primary Prevention Efforts

Deafness

Deception

Decriminalization

Defense Mechanisms

Delay of Gratification

Delinquency

Delinquency Trajectories

Delinquent Youth with Disabilities

Delirium

Delusion

Dependency Court Processes

Dependency in Law

Depressive Symptoms

Designer Drugs

Desistance from Crime and Delinquency

Detention of Alien Juveniles

Developmental

Developmental Assets

Developmental Contextualism

Developmental Periods

Deviancy

Deviancy Training

Diary Methods

Dietary Patterns

Digital Divides
Disability

Disciplining

Discrimination

Disease

Dispositions in Law

Dissociation

Dissociative Disorders

Dissociative Identity Disorder

Diversion Programs

Divorce

Domestic Violence

Doping

Double Standards

Dress Codes and Uniforms

Drinking Game Playing: A Prevalent and Risky Activity Among Youth

Driving and Drivers

Drug Sellers and Distributors

Due Process of Law

Duty to Protect in Law

Dyslexia

Dysphoria

Eating Disorders

Ecstasy Use

Educational Aspirations

Effortful Control

Ego Identity

Egocentrism

Emancipation

Emergency Contraception

Emerging Adulthood

Emotion Regulation

Emotional Abuse

Emotional Intelligence

Emotional Reactivity

Enuresis and Encopresis

Envy

Epilepsy: Psychological and Psychiatric Aspects in Adolescence

Epistemic Cognition

Equal Access Act

Equal Protection Laws

Ethnic Identity

Ethnic Identity Formation

Ethnographic Methods

Evidence-Based Practice

Evolutionary Perspectives on Adolescence 
Executive Function

Executive System

Exhibitionism

Existential Anxiety

Exit Therapy

Expectancy Value Models

Experimental and Quasi-Experimental Methods

Expulsions and Suspensions from School

Externalizing and Internalizing Symptoms

Extracurricular Activity Participation

Extraversion

Extremism

Fair Labor Standards Act

Faith

Family and Educational Rights and Privacy Act

Family Development Theory

Family Group Decision-Making

Family Immunity Doctrine

Family Meals

Family Policy

Family Resiliency

Family Risk and Needs Assessment

Family Systems Theory

Family-Based Prevention Programs

Family-Based Therapy

Fanaticism

Fantasy

Fast Foods

Fatherhood

Fathers' Rights Outside of Marriage

Fear of Crime

Fears

Femininity

Fetal Alcohol Spectrum Disorders

Fetal Effects

Financial Socialization

Financial Stress

Firesetting

Flirting

Flow

Forbidden Fruit

Forensic Consulting

Foresightedness

Forgiveness

Formal Operations

Foster Care

Free Will
Friendship Characteristics

Friendships and Adjustment

Frontal Lobe

Fundamental Rights

Future Orientation

Gambling

Gangs

Gateway Drug Use

Gay-Straight Alliances

Gender Coding

Gender Complementation

Gender Dysphoria

Gender Identification

Gender Identity

Gender Identity Disorder

Gender Intensification

Gender Role and Identity

Gender Role Conflict: Boyhood in Distress

Gendered Juvenile Justice

General Strain Theory

Generativity

Genetic Influences and Criminal Careers

Giftedness: Asset and Vulnerability

Goal Structures: Their Role in Promoting Early

Adolescents' Peer Relationships and

Academic Achievement

Goals

Gonadarche

Gossip

Goth Culture

Grade Retention: Assessing Its Role in Students' Academic and Personal Wellbeing Outcomes

Graffiti

Grandparent-Adolescent Relationship

Gratitude

Gray Matter

Group Homes

Group Identification

Growth Hormone

Guardian Ad Litem

Guardianship

Habeas Corpus

Hallucinations

Hallucinogens

Happiness

Harm Reduction

Hate Crimes 
Hateful Expression Rights

Hazing

Health Beliefs

Health Literacy

Help-Negation

Help-Seeking

Heritability

Heterosocial Competence

High School Dropouts

Hijab

Home Schooling

Homesickness

Homework

Homophily

Homophobia

Hooking Up: Teenage Casual Sex

Hope

Hopelessness

Human Immunodeficiency Virus (HIV) Infection

Human Papillomavirus (HPV) and HPV Vaccines

Humiliation

Humor

Hyperactivity

Hypnosis

Identity Distress

Identity Formation

Identity Processes

Identity Status

Idols and Idolization

Immigrants' Linguistic Adaptation

Immigration

Impostor Phenomenon

Impulsivity

In Loco Parentis

Incarcerated Parents

Incarcerated Youth

Indian Child Welfare Act

Individualized Education Programs

Individuals with Disabilities Education Act

Infatuation

Information Management

Informational Rights

Informed Consent and Assent

Inhalant Use

Injuries

Injury Prevention

Institutional Commitments
Intellectual Disability

Intelligence

Intensive Family Preservation

Internalizing and Externalizing Problems

International Human Rights

Internet Effects

Internships

Interrogation and the Waiver of Rights

Intrinsic and Extrinsic Motivation

Involuntary Commitments

Invulnerability

Jealousy

Jury Trial Rights in Juvenile Court

Juvenile Court Processes

Juvenile Court Rationales and Models

Juvenile Court Transfers

Juvenile Death Penalty

Juvenile Drug Courts

Juvenile Homicide in the Twenty-First Century

Juvenile Justice and Delinquency Prevention Act

Juvenile Probation

Juvenile Risk Assessment

Juvenile Sex Offenders

Juvenility and the Juvenile Transition

Kissing

Lability

Language Brokering

Language Development and Literacy

Latchkey Children

Leadership Development and Gifted Students

Learning Strategies

Legal Methods

Lesbian and Gay Parenting

Life Course Theory

Life Events

Life Goals: Intrinsic and Extrinsic Pursuits

Life Satisfaction

Life Sentences

Life-Story Work

Loneliness

Loners

Longitudinal Designs

Lying

Magical Thinking

Mainstreaming

Malingering

Malls 
Marijuana Use

Marital Distress and Conflict

Marital Rights

Marriage

Masculinity

Masturbation

Mattering

Maturation

Mature Minor Doctrine

Maturity of Judgment

Meaning in Life

Meanness

Measurement Validity

Media Literacy and Health Promotion

Media Violence

Menarche

Mental Health

Mental Health Checkups

Mental Health Policy

Mental Health Screening

Mental Health Stigma

Mentoring

Meta-Analysis

Methamphetamine Use

Microaggressions

Mindful Parenting

Mindfulness Meditation

Minnesota Multiphasic Personality Inventory for Adolescents

Missing Children Act

Model Minority Identities

Mood Disorders

Moral Development and Moral Behavior

Moral Disengagement and Antisocial Behavior

Moral Identity

Moral Reasoning Assessment

Mortality Judgments

Motherhood

Multicultural Education

Multiracial Identity

Multisystemic Therapy

Music

Music Therapy

Myelin

Narcissism

Narcolepsy

Narrative Identity
National Identity

Natural Disasters

Neighborhoods

Neocortex

Neuroimaging and Electroencephalography

Neurons and Neurotransmitters

Neuroticism

Nightmares

No Child Left Behind Act

Nomothetic and Ideographic

Nonparental Adults

Nonsuicidal Self-Injury

Nontraditional Families in Law

Normality

Obesity and Overweight

Objectification Theory

Obscene and Indecent Expressions

Obsessive Compulsive Disorder

Occipital Lobe

Occupational Aspirations

Oedipus Complex

Online Health Care

Openness to Experience

Opiates

Oppositional Defiant and Conduct Disorders

Optimal Functioning

Out-of-School Time Programs

Overachievement

Panic Disorder

Paranormal and Supernatural Beliefs

Parens Patriae

Parent Abuse

Parental Alienation Syndrome

Parental Bereavement

Parental Deployments

Parental Illness

Parental Involvement

Parental Monitoring

Parental Problem Drinking and Alcoholism

Parental Responsibility Laws

Parental Rights

Parental Rights' Limits

Parental Rights' Termination

Parentification

Parenting Styles

Parietal Lobe

Parole 
Parricide Offenders in the Twenty-First Century

Peak Experiences

Pedophilia

Peer Influences

Peer Interventions

Perfectionism

Personality

Personality Assessment and Maturation

Personality Disorders

Pets

Physical Abuse

Physical Disability and Self-Esteem

Place Attachment in Adolescence

Play/Activity Therapy

Policing Juveniles

Political Expression Rights

Popularity

Pornography

Posttraumatic Stress Disorder

Poverty

Prefrontal Cortex

Pregnancy Intentions

Pregnancy Resolutions

Prepartying and Pregaming

Prescription Drug Misuse

Prevention Programs

Preventive Detentions

Pride

Prison Awareness Programs

Prisons

Privacy

Private Speech

Proactive and Reactive Aggression

Probation

Problem Behavior Syndrome

Procrastination

Program Evaluation

Prom

Prosocial Behavior

Prostitution

Psychiatric Disorders: Classifications and

Diagnoses

Psychoanalytic Therapies

Psychodynamic Understandings

Psychopathy

Psychosexual Stages

Psychotic-Like Experiences
PTSD Among Youth from Violent Impoverished Communities

PTSD in Young Soldiers from Violent Impoverished Communities

Pubertal Timing

Puberty

Puberty Rites

Public Policy

Purpose

Pygmalion Effect

Qualitative Methods

Quality of Life

Quantitative Methods

Race and Juvenile Justice Decision-Making

Racial and Ethnic Discrimination

Racial Pride

Racism

Rape

Rape Trauma Syndrome

Reactive Attachment Disorder

Reasoning

Rebelliousness

Recidivism

Refugees

Reintegrative Shaming Theory

Rejection Sensitivity

Relationship Networks

Reliability

Religious Expression Rights

Religiousness in Adolescence and Emerging Adulthood

Reputations

Residency Requirements

Residential Treatment

Resilience

Resistance and Conformity

Resistance to Treatment

Restitution

Restorative Justice

Revenge

Rights Knowledge, Reasoning, and Attitudes

Risk Behavior

Risk-Taking

Role Models

Romantic Experiences

Rorschach Inkblot Method

Routine Activities Theory 
Rumination

Runaway and Homeless Youth Act

Runaway Youth

Sadistic Personality Disorder

Safe and Drug-Free Schools and Communities Act

Safe Space

Scapegoating

Schema

Schizophrenia

Schizotypy

School Belonging

School Climate

School Connectedness

School Discipline

School Refusal Behavior and Absenteeism

School Size

School Transitions and Risks

School-Based Health Centers

Searches and Seizures in Schools

Segregation and Desegregation

Self-Report

Self-Actualization

Self-Concept

Self-Concept Clarity

Self-Consciousness

Self-Construal in a Cultural Context

Self-Control Theory

Self-Determination

Self-Disclosure

Self-Discrepancies

Self-Efficacy

Self-Efficacy and Adolescents' Health

Self-Esteem

Self-Monitoring

Self-Perception

Self-Reflection

Self-Regulation

Sensation Seeking

Sensational Interests

Sense of Entitlement

Separation Anxiety

Separation-Individuation

Serotonin

Service-Learning

SES

Sex Roles and Gender Roles
Sex Trafficking into the United States

Sex Trafficking Within the United States

Sex Trafficking Worldwide

Sexism

Sexual Addiction

Sexual Debut

Sexual Expression Rights

Sexual Harassment

Sexual Health

Sexual Minority Youth

Sexual Orientation and Identity Labels

Sexual Trajectories

Sexual Victimization

Sexuality Education

Sexuality Education Sources

Sexually Violent Predators

Shame and Guilt

Sibling Influences

Sibling Maltreatment

Sibling Rivalry

Sleep Deprivation

Sleep Disturbances

Smart Drugs

Social Brain

Social Capital Theory for Youth Studies

Social Cognition

Social Competence

Social Connectedness

Social Control Theory

Social Disorganization Theory

Social Exclusion and Subculture

Social Exclusion in Adolescence

Social Inoculation

Social Intelligence

Social Justice Theory

Social Learning Theory

Social Networking in Online and Offline Contexts

Social Reasoning

Social Skills Training

Social Support

Social Trust

Social Withdrawal

Somatic Complaints

Specific Learning Disorder

Spiritual Development

Sport and the Development of Family, School,

Peer, and Community Strengths 
Sport and Youth Development

Stalking

Status Offenses and Offenders

Statutory Rape

Steroid Use

Stigmatization

Storm and Stress

Stress

Stress Management

Strip Searches and Students' Rights

Student Drug Testing

Student Engagement

Substance Abuse Treatment

Substance Use Risk and Protective Factors

Suicidality

Suicide

Suicide Pacts and Suicide Clusters

Summer Camps

Synapse

Taxonomies of Delinquents

Teen Courts

Temperament

Temporal Lobe

Terrorism

Testimonial Competency

Thematic Apperception Test

Theory of Mind

Therapeutic Foster Care

Thought Disorder

Thriving and Sparks

Tic, Tourettes, and Related Disorders

Tobacco Use

Tolerance
Training for Effective Parenting

Trajectories of Aggressive-Disruptive Behavior

Transactional Models

Transgender Youth

Transitioning from Care

Transsexualism

Triangulation

Trophy Kids

Truant Youth

Underachievement

Underachievers

Underclass

Unfit Parents

Validity

Vegetarianism

Video Games

Virginity Loss

Vocational Education

Vouchers

Vulnerability

Weapons Carrying

Wellness

Wet Dream

White Matter

Wilderness Therapy

Wisdom

Work and Antisocial Behavior

Working Memory

Wraparound Interventions

Youth Research Traditions

Zero-Tolerance Policies 



\section{About the Editor}

Roger J. R. Levesque, J.D., Ph.D., is Professor of Criminal Justice and (Affiliate) of Law at Indiana University in Bloomington, Indiana. He received his J.D. from Columbia University School of Law and his Ph.D. in Cultural and Developmental Psychology from the University of Chicago. In addition to authoring over 50 articles and book chapters, Professor Levesque has published over a dozen books, most of which deal with the legal regulation of adolescence and family life. His books have earned awards from the Society for Research on Adolescence as well as the American Psychology and Law Society. The Association for Psychological Science (APS) (previously the American Psychological Society) has elected him Fellow in recognition of his outstanding contributions to developmental science; and the American Psychological Association (APA) has elected him Fellow in recognition of his contributions to the fields of psychology and law, family policy, as well as social issues (three separate divisions). Professor Levesque currently serves as Editor-in-Chief of Springer's Journal of Youth and Adolescence as well as Adolescent Research Review. In addition, he serves as editor of Springer's highly successful Advancing Responsible Adolescent Development book series. 



\section{Advisory Board}

John W. Berry Department of Psychology, Queen's University at Kingston, Kingston, ON, Canada

William Damon Stanford University, School of Education, Stanford, CA, USA

Jacquelynne S. Eccles Population Studies Center, University of Michigan, Ann Arbor, MI, USA

David P. Farrington University of Cambridge, Institute of Criminology, Cambridge, UK

Sandra Graham Department of Education, University of California, Los Angeles, Los Angeles, CA, USA

Daniel Offer Department of Psychiatry and Behavioral Sciences, Northwestern University Feinberg School of Medicine, Chicago, IL, USA

Ronald Roesch Department of Psychology, Simon Fraser University, Burnaby, BC, Canada

Stephen T. Russell Norton School of Family and Consumer Sciences, University of Arizona, Tucson, AZ, USA

Elizabeth S. Scott Vice Dean \& Harold R. Medina Professor of Law, Columbia Law School, New York, NY, USA

Rainer K. Silbereisen Department of Developmental Psychology, University of Jena, Jena, Germany

Michael Windle Behavioral Sciences and Health Education, Rollins School of Public Health, Emory University, Atlanta, GA, USA 



\section{Contributors}

Judit Abad Department of Personality, Assessment and Psychological Treatments, University of Barcelona, Barcelona, Spain

Frances P. Abderhalden Department of Criminology and Criminal Justice, University of West Florida, Pensacola, FL, USA

John R. Z. Abela Department of Psychology, University of Illinois, UrbanaChampaign, NJ, USA

Mona M. Abo-Zena Department of Education and Human Development, Brown University, Providence, RI, USA

Jemel P. Aguilar Center for Social Work Research, Austin School of Social Work, University of Texas at Austin, Austin, TX, USA

Rosa Alati School of Population Health and Centre for Youth Substance Abuse Research, University of Queensland, Herston, QLD, Australia

Lisa Albrecht Institute of Health, Nutrition, and Sport Sciences, EuropaUniversität Flensburg, Flensburg, Germany

P. Alex Linley Centre of Applied Positive Psychology, The Venture Centre, University of Warwick Science Park, Coventry, UK

Pierre K. Alexandre Department of Mental Health, Johns Hopkins Bloomberg School of Public Health, Baltimore, MD, USA

La Rue Allen Department of Applied Psychology, Steinhardt School of Culture, Education, and Human Development, New York University, New York, NY, USA

Michal Al-Yagon Constantiner School of Education, Tel-Aviv University, Ramat-Aviv, Israel

Vanessa Anderson City University of New York, New York, NY, USA

Dawn Anderson-Butcher College of Social Work, The Ohio State University, Columbus, OH, USA 
Romina Angeleri Department of Psychology, University of New Mexico, Albuquerque, NM, USA

Elizabeth K. Anthony School of Social Work, Arizona State University, Phoenix, AZ, USA

Robert Apel School of Criminal Justice, University at Albany, State University of New York, Albany, NY, USA

James J. Appleton Office of Research and Evaluation, Instructional Support Center, Gwinnett County Public Schools, Suwanee, GA, USA

Robert P. Archer Department of Psychiatry and Behavioral Sciences, Eastern Virginia Medical School, Norfolk, VA, USA

Abigail R. Archibald Department of Psychiatry, Massachusetts General Hospital, Boston, MA, USA

Nina Asher Department of Curriculum and Instruction, University of Minnesota-Twin Cities, Minneapolis, MN, USA

Adrian F. Ashman School of Education, University of Queensland, Brisbane, QLD, Australia

Karim Assous Department of Psychology, University of Maine, Orono, ME, USA

Shalhevet Attar-Schwartz School of Social Work and Social Welfare, The Hebrew University of Jerusalem, Jerusalem, Israel

María Dolores Avia Department of Personality, Assessment, and Clinical Psychology, Faculty of Psychology, Complutense University of Madrid, Somosaguas, Pozuelo de Alarcón, Madrid, Spain

Martica Bacallao Department of Social Work, University of North Carolina Pembroke, Pembroke, NC, USA

Michal Bak University of Western Ontario located in London, Ontario, Canada

Christine Baker-Smith Quantitative Methods in the Social Sciences Program (QMSS), Institute for Social and Economic Research and Policy (ISERP), Columbia University, New York, NY, USA

Oscar A. Baldelomar University of Minnesota, Morris, MN, USA

Grant T. Baldwin Centers for Disease Control and Prevention, National Center for Injury Prevention and Control, Atlanta, GA, USA

Michael F. Ballesteros Centers for Disease Control and Prevention, National Center for Injury Prevention and Control, Atlanta, GA, USA

J. C. Barnes School of Criminal Justice, University of Cincinnati, Cincinnati, $\mathrm{OH}, \mathrm{USA}$

Lynn A. Barnett Department of Recreation, Sport and Tourism, University of Illinois at Urbana-Champaign, Champaign, IL, USA 
Carolyn McNamara Barry Department of Psychology, Loyola University Maryland, Baltimore, MD, USA

Susan A. Basow Department of Psychology, Lafayette College, Easton, PA, USA

Loretta E. Bass Department of Sociology, University of Oklahoma, Norman, OK, USA

Cherylynn Bassani University of the Fraser Valley, Abbotsford, BC, Canada

Marta Bassi Dipartimento di Scienze Cliniche Luigi Sacco, Università degli Studi di Milano, Milano, Italy

Samantha Bates College of Social Work, The Ohio State University, Columbus, OH, USA

Linda L. Batto The University of Texas at Arlington, Arlington, TX, USA

Maude Beaudry-Cyr Department of Criminology, University of South Florida, Tampa, FL, USA

Kevin M. Beaver College of Criminology and Criminal Justice, Florida State University, Tallahassee, FL, USA

Stephen P. Becker Division of Behavioral Medicine and Clinical Psychology, Cincinnati Children's Hospital Medical Center, Cincinnati, OH, USA

Troy E. Beckert Emma Eccles Jones College of Education and Human Services, Utah State University, Logan, UT, USA

Amy Bellmore Department of Educational Psychology, University of Wisconsin-Madison, Madison, WI, USA

H. Eric Bender San Francisco, CA, USA

Aprile D. Benner Department of Human Development and Family Sciences, University of Texas at Austin, Austin, TX, USA

Peter L. Benson Search Institute, Minneapolis, MN, USA

Karen M. Benzies University of Calgary, Calgary, AL, Canada

Lynda Bergsma Mel and Enid Zuckerman College of Public Health, The University of Arizona, Tucson, AZ, USA

Ruth A. Berman Department of Linguistics, Tel Aviv University, Ramat Aviv, Israel

Steven L. Berman Department of Psychology, University of Central Florida, Daytona Beach, FL, USA

Julia M. Becerra Bernard Department of Counseling and Human Services, East Tennessee State University, Johnson City, TN, USA

Shannon S. C. Bert Department of Human Relations and Women's and Gender Studies, University of Oklahoma, Norman, OK, USA 
Rosalyn M. Bertram School of Social Work, University of Missouri-Kansas City, Kansas City, MO, USA

Michael D. Berzonsky Department of Psychology, State University of New York College at Cortland, Cortland, NY, USA

J. Betkowski Division of Child and Adolescent Psychiatry, Center for School Mental Health, University of Maryland School of Medicine, Baltimore, MD, USA

D. Betsy McCoach Educational Psychology Department, University of Connecticut, Storrs, CT, USA

Sarah-Jayne Blakemore UCL Institute of Cognitive Neuroscience, London, UK

Christopher Blazina Department of Psychology, Tennessee State University, Nashville, TN, USA

Leonardo Bobadilla Pacific University, School of Professional Psychology, Hillsboro, OR, USA

Joseph M. Boden Department of Psychological Medicine, University of Otago, Christchurch School of Medicine and Health Sciences, Christchurch, New Zealand

Kimber Bogard National Academies of Science, Engineering and Medicine, Washington, DC, USA

Institute of Human Development and Social Change, Steinhardt School of Culture, Education, and Human Development, New York University, New York, NY, USA

Tom F. M. ter Bogt Department of Interdisciplinary Social Science, Utrecht University, Utrecht, The Netherlands

Robert M. Bohm Department of Criminal Justice and Legal Studies, University of Central Florida, Orlando, FL, USA

Kipling M. Bohnert Department of Epidemiology, Michigan State University, East Lansing, MI, USA

C. L. Bokhorst Developmental and Educational Psychology Unit, Leiden University, Leiden, The Netherlands

Larry M. Bolen Department of Psychology, East Carolina University, Greenville, NC, USA

Giacomo Bono California State University, Carson, CA, USA

Jessika H. Bottiani Curry School of Education, University of Virginia, Charlottesville, VA, USA

Anne Bowker Department of Psychology, Carleton University, Ottawa, ON, Canada 
Julie C. Bowker Department of Psychology, University at Buffalo, The State University of New York, Buffalo, NY, USA

Ty W. Boyer Department of Psychology, Georgia Southern University, Statesboro, GA, USA

Catherine P. Bradshaw Curry School of Education, University of Virginia, Charlottesville, VA, USA

Susan J. T. Branje Research Centre Adolescent Development, Utrecht University, Utrecht, The Netherlands

Christopher Bratt Centre for Child and Adolescent Mental Health (Eastern and Southern Norway), Oslo, Norway

Sue C. Bratton University of North Texas, Denton, TX, USA

Tim Brennan Northpointe Institute, Peachtree City, GA, USA

Jeffrey A. Bridge Department of Pediatrics, The Research Institute at Nationwide Children's Hospital, Ohio State University, Columbus, OH, USA

Cynthia A. Brown Department of Criminal Justice and Legal Studies, University of Central Florida, Orlando, FL, USA

Michael B. Brown Thomas Harriot College of Arts and Sciences, East Carolina University, Greenville, NC, USA

Johna Hughes Bruton Bruton Consulting, Inc., Burlington, NC, USA

Ann Buchanan Centre for Parenting and Children, Department of Social Policy and Social Work, University of Oxford, Oxford, UK

Christy M. Buchanan Department of Psychology, Wake Forest University, Winston-Salem, NC, USA

Kirsten L. Buist Department of Clinical Child and Family Studies, Utrecht University, Utrecht, The Netherlands

Gabriel Bukobza School of Education, Tel Aviv University School of Education, Tel Aviv, Israel

Matthew J. Bundick The Pennsylvania State University, University Park, PA, USA

Alison S. Burke Department of Criminology and Criminal Justice, Southern Oregon University, Ashland, OR, USA

Stephanie Burnett UCL Institute of Neurology, London, UK

Anthony L. Burrow Department of Human Development, Cornell University, Ithaca, NY, USA

Sheretta T. Butler-Barnes George Warren Brown School of Social Work, Washington University in St. Louis, St. Louis, MO, USA

James P. Byrnes Psychological Studies in Education, Temple University, Philadelphia, PA, USA 
Joseph L. Calles Jr. Department of Psychiatry, Michigan State University/ Kalamazoo Center for Medical Studies, Kalamazoo, MI, USA

Mark Cameron Department of Social Work, Southern Connecticut State University, New Haven, CT, USA

Mary Ann Campbell Centre for Criminal Justice Studies and Department of Psychology, University of New Brunswick, Saint John, NB, Canada

Kali Van Campen Family Studies and Human Development, University of Arizona, Tucson, AZ, USA

Deborah M. Capaldi Oregon Social Learning Center, Eugene, OR, USA

Alan Carr School of Psychology, University College Dublin, Belfield, Dublin, Ireland

Annemaree Carroll School of Education, The University of Queensland, Brisbane, QLD, Australia

James Bucky Carter English Education, University of Texas at El Paso English Department, El Paso, TX, USA

Rebecca Carter School of Integrative Studies, George Mason University, Fairfax, VA, USA

Scottye J. Cash College of Social Work, The Ohio State University, Columbus, OH, USA

Omni Cassidy Department of Medical and Clinical Psychology, Uniformed Services University of the Health Sciences, Bethesda, MD, USA

Edward M. Castillo Department of Emergency Medicine, University of California, San Diego, CA, USA

Jory M. Catalpa University of Minnesota, St. Paul, MN, USA

Elizabeth Cauffman Psychology and Social Behavior and Education, University of California, Irvine, CA, USA

Peggy L. Ceballos University of North Texas, Denton, TX, USA

Carla Cesaroni University of Ontario Institute of Technology, Oshawa, ON, Canada

Raymond C. K. Chan CAS Key Laboratory of Mental Health, Institute of Psychology, Chinese Academy of Sciences, Beijing, China

Anita Chandra RAND Corporation, Arlington, VA, USA

Constance L. Chapple Department of Sociology, University of Oklahoma, Norman, OK, USA

Ruby Charak Department of Psychological Science, The University of Texas-Rio Grande Valley, College of Liberal Arts, Edinburg, TX, USA

Kathy E. Charles School of Applied Sciences, Edinburgh Napier University, Edinburgh, UK 
Chuansheng Chen Department of Psychology and Social Behavior, School of Social Ecology, University of California - Irvine, Irvine, CA, USA

May S. Chen Department of Health Behavior, University of North Carolina at Chapel Hill, Chapel Hill, NC, USA

Wan-Yi Chen College of Human Ecology, School of Social Work, Syracuse University, Syracuse, NY, USA

Howard D. Chilcoat Department of Mental Health, Johns Hopkins Bloomberg School of Public Health, Baltimore, MD, USA

GlaxoSmithKline Worldwide Epidemiology, GlaxoSmithKline, Research Triangle Park, NC, USA

Gwendolyn Childs School of Nursing, University of Alabama at Birmingham, Birmingham, AL, USA

Kristina Childs Department of Psychology, University of New Orleans, New Orleans, LA, USA

Ming Ming Chiu Department of Educational Studies, Purdue University, West Lafayette, IN, USA

Catherine P. Chou Department of Psychology, Southeast Missouri State University, Cape Girardeau, MO, USA

Brian D. Christens School of Human Ecology, University of Wisconsin, Madison, WI, USA

Antonius H. N. Cillessen Behavioural Science Institute, Developmental Psychology, Radboud Universiteit Nijmegen, Nijmegen, The Netherlands

Trenette Clark Goings School of Social Work, University of North Carolina at Chapel Hill, Chapel Hill, NC, USA

Joseph R. Cohen Department of Psychology, University of Illinois, UrbanaChampaign, NJ, USA

Craig R. Colder Department of Psychology, State University of New York University at Buffalo, Buffalo, NY, USA

Jonathan S. Comer New York State Psychiatric Institute, Division of Child Psychiatry, Columbia University, New York, NY, USA

R. Dawn Comstock College of Medicine, Department of Pediatrics and College of Public Health, Division of Epidemiology, The Ohio State University, Columbus, OH, USA

Center for Injury Research and Policy, Columbus Children's Hospital, Columbus, $\mathrm{OH}$, USA

Christine A. Conelea Department of Psychology, University of WisconsinMilwaukee, Milwaukee, WI, USA

Daniel F. Connor Department of Psychiatry, University of Connecticut Health Center, Farmington, CT, USA 
David E. Conroy Departments of Kinesiology and Human Development and Family Studies, The Pennsylvania State University, University Park, PA, USA Department of Preventive Medicine, Northwestern University, Chicago, IL, USA

Catherine Cook-Cottone Department of Counseling, School, and Educational Psychology, University at Buffalo, State University of New York, Buffalo, NY, USA

Daniel G. Cooper Institute on Social Exclusion, Adler University, Chicago, IL, USA

Robert J. Coplan Department of Psychology, Carleton University, Ottawa, ON, Canada

Kenneth Corvo College of Human Ecology, School of Social Work, Syracuse University, Syracuse, NY, USA

Elizabeth A. Courtney New York State Psychiatric Institute, New York, NY, USA

Hofstra University, Hempstead, NY, USA

Carrie Coward-Bucher Department of History, Culture, and Society, Baker University, Baldwin City, KS, USA

Jamie Craig Psychology and Behavior Center, Brandon, MS, USA

David Crampton Jack, Joseph and Morton Mandel School of Applied Social Sciences, Case Western Reserve University, Cleveland, OH, USA

William D. Crano Psychology Department, Division of Behavioral and Organizational Sciences, Claremont Graduate University, Claremont, CA, USA

Sarah A. Crawley Department of Psychology, Temple University, Philadelphia, PA, USA

Carla Crespo Faculty of Psychology and Educational Sciences, University of Coimbra, Coimbra, Portugal

Elisabetta Crocetti Alma Mater Studiorum University of di Bologna, Bologna, Italy

Jennifer Riedl Cross Center for Gifted Education, College of William and Mary, Williamsburg, VA, USA

Donna Cross Edith Cowan University and Telethon Kids Institute in Western Australia, Subiaco, Australia

Qiana R. Cryer-Coupet Department of Social Work, North Carolina State University, Raleigh, NC, USA

Gretchen J. Cutler Division of Epidemiology and Community Health, School of Public Health, University of Minnesota, Minneapolis, MN, USA 
Chelsea F. Dale Department of Psychiatry, Massachusetts General Hospital, Boston, MA, USA

Lorenza Dallago Department of Social and Developmental Psychology, University of Padova, Padova, Italy

Danielle H. Dallaire Psychology Department, The College of William and Mary, Williamsburg, VA, USA

Lavinia E. Damian Babeș-Bolyai University, Cluj-Napoca, Romania

Jeffrey A. Daniels Department of Counseling, Rehabilitation Counseling and Counseling Psychology, West Virginia University, Morgantown, WV, USA

Jennifer L. Dartt School of Social Work, University of Missouri-Kansas City, Kansas City, MO, USA

Carol Dashiff School of Nursing, University of Alabama at Birmingham, Birmingham, AL, USA

Joanne Davila Department of Psychology, Stony Brook University, Stony Brook, NY, USA

J. Davis Department of Athletics, Ohio State University, Columbus, OH, USA

Terry C. Davis Departments of Medicine and Pediatrics, Louisiana State University Health Sciences Center, Shreveport, LA, USA

Hanneke de Graaf Rutgers, Utrecht, The Netherlands

Rebecca S. Define School of Social Work, Saint Louis University, St Louis, MO, USA

Marco Del Giudice Department of Psychology, University of New Mexico, Albuquerque, NM, USA

Sergio V. Delgado Department of Pediatrics, Division of Child and Adolescent Psychiatry, Cincinnati Children's Hospital Medical Center, Cincinnati, $\mathrm{OH}$, USA

Antonella Delle Fave Dipartimento di Scienze Cliniche Luigi Sacco, Università degli Studi di Milano, Milano, Italy

Katy L. DeLong Department of Psychology, West Virginia University, Morgantown, WV, USA

Marc J. M. H. Delsing Praktikon, Radboud University Nijmegen, Nijmegen, The Netherlands

Danielle M. Denenny Semel Institute for Neuroscience and Human Behavior, University of California, Los Angeles, Los Angeles, CA, USA

Roger Desmond School of Communication, University of Hartford, West Hartford, CT, USA 
Mandeep K. Dhami Department of Psychology, Middlesex University, Hendon, London, UK

David DiLillo Department of Psychology, Clinical Psychology Training Program, University of Nebraska - Lincoln, Lincoln, NE, USA

Melanie A. Dirks Department of Psychology, McGill University, Montreal, QC, Canada

Laura M. L. Distel Department of Psychology, Loyola University Chicago, Chicago, IL, USA

Andrea L. Dixon Georgia State University, Atlanta, GA, USA

Leonard A. Doerfler Department of Psychiatry, University of Massachusetts Medical School, Worcester, MA, USA

Department of Psychology, Assumption College, Worcester, MA, USA

J. Douglas Coatsworth Department of Human Development and Family Studies, Colorado State University, Fort Collins, CO, USA

Sara Douglass T. Denny Sanford School of Social and Family Dynamics, Arizona State University, Tempe, AZ, USA

Anna Beth Doyle Department of Psychology, Concordia University, Montreal, QC, Canada

Lauren M. Duerson Department of Counselor Education, Clemson University, Clemson, SC, USA

Larissa G. Duncan Department of Human Development and Family Studies, School of Human Ecology, University of Wisconsin-Madison, Madison, WI, USA

Kevin Durkin School of Psychological Sciences and Health, Strathclyde University, Strathclyde, Glasgow, UK

Nicholas R. Eaton Department of Psychology, Stony Brook University, Stony Brook, NY, USA

Robert P. Eckstein Departments of Psychology and Justice Studies, Prevention Innovations Research Center, University of New Hampshire, Durham, $\mathrm{NH}$, USA

Julian H. Edbrooke-Childs University College London and Anna Freud Centre, London, UK

Aubrey L. Edson Child and Family Psychiatry, Alpert Medical School of Brown University, Rhode Island, NJ, USA

Katie M. Edwards Department of Psychology and Women's Studies Program, Prevention Innovations Research Center, University of New Hampshire, Durham, NH, USA

Vincent Egan Centre for Family and Forensic Psychology, Department of Psychiatry and Applied Psychology, University of Nottingham, Nottingham, UK 
Maurice J. Elias Psychology Department, Rutgers University, Piscataway, NJ, USA

Jaklin Eliott School of Public Health, The University of Adelaide, Adelaide, SA, Australia

Jeff Elison Department of Psychology, Adams State University, Alamosa, CO, USA

Jill M. Emanuele Bronx Children's Psychiartic Centre, Bronx, NY, USA

Andrea Ettekal Tufts University, Medford, MA, USA

N. Evangelista Division of Child and Adolescent Psychiatry, Center for School Mental Health, University of Maryland School of Medicine, Baltimore, MD, USA

Caroline B. R. Evans School of Social Welfare, University of Kansas, Lawrence, KS, USA

Sara Z. Evans Department of Criminology and Criminal Justice, University of West Florida, Pensacola, FL, USA

Sarah E. Evans Department of Psychology, Clinical Psychology Training Program, University of Nebraska - Lincoln, Lincoln, NE, USA

Jessica Eye Department of Psychology, Lehigh University, Bethlehem, PA, USA

Jay S. Fagan School of Social Work, Temple University, Philadelphia, PA, USA

Beverly S. Faircloth School of Education, University of North Carolina at Greensboro, Greensboro, NC, USA

Kostas A. Fanti Department of Psychology, University of Cyprus, Nicosia, Cyprus

Amy Feldman Farb Department of Human Development and Family Sciences, The University of Texas at Austin, Austin, TX, USA

Jaelyn R. Farris Department of Psychology, Youngstown State University, Youngstown, OH, USA

Susan P. Farruggia University of Illinois at Chicago, Chicago, IL, USA

Alan Feldberg Abraxas Youth Center, South Mountain, PA, USA

Richard S. Feldman Department of Psychiatry, New York State Psychiatric Institute and Columbia University, New York, NY, USA

Christopher J. Ferguson Department of Behavioral, Applied Sciences and Criminal Justice, Texas A \& M International University, Laredo, TX, USA

Stetson University, DeLand, FL, USA

Gail M. Ferguson Department of Psychology, Knox College, Galesburg, IL, USA 
Laurence Fillisetti Université de Caen Basse-Normandie, Caen, France

Christopher Fischer Department of Psychiatry and Behavioral Sciences, University of Southern California, Los Angeles, CA, USA

Paula J. Fite Clinical Child Psychology Program and Consortium for Translational Research on Aggression and Drug Abuse (ConTRADA), University of Kansas, Lawrence, KS, USA

Michele J. Fleming University of Canberra, Bruce, ACT, Australia

Lisa M. Fletcher Department of Psychology, The University of Alabama, Tuscaloosa, AL, USA

Andrew Flood Division of Epidemiology and Community Health, School of Public Health, University of Minnesota, Minneapolis, MN, USA

Eduardo Fonseca-Pedrero Department of Educational Sciences, University of La Rioja, Logroño, Spain

Carlos III Health Institute, Research Centre in the Mental Health Network (CIBERSAM), Madrid, Spain

Rex Forehand Department of Psychological Science, Dewey Hall, University of Vermont, Burlington, VT, USA

Mirae J. Fornander University of Nevada, Las Vegas, Las Vegas, NV, USA

Maria Forns Department of Personality, Assessment and Psychological Treatments, University of Barcelona, Barcelona, Spain

Vangie A. Foshee Gillings School of Global Public Health, University of North Carolina at Chapel Hill, Chapel Hill, NC, USA

Jeremy K. Fox Department of Psychology, Montclair State University, Montclair, NJ, USA

Cynthia Franklin School of Social Work, University of Texas, Austin, TX, USA

Martin E. Franklin Department of Psychiatry, University of Pennsylvania School of Medicine, Philadelphia, PA, USA

Child/Adolescent OCD, Tic, Trichotillomania and Anxiety Group (COTTAGe), Philadelphia, PA, USA

Shana A. Franklin Department of Psychology, University of WisconsinMilwaukee, Milwaukee, WI, USA

Mark Fraser Psychology Department, Laurentian University, Sudbury, ON, Canada

Elisabeth A. Frazier Psychiatry and Human Behavior, The Alpert Medical School of Brown University, East Providence, RI, USA

Beth W. Freeburg School of Education, Saint Louis University, St. Louis, MO, USA 
Jennifer B. Freeman Child/Adolescent OCD, Tic, Trichotillomania and Anxiety Group (COTTAGe), Philadelphia, PA, USA

Paul J. Frick Louisiana State University, Baton Rouge, LA, USA

Australian Catholic University, Melbourne, VIC, Australia

Jeffrey J. Froh Department of Psychology, Hofstra University, Hempstead, NY, USA

Kim Fromme Department of Psychology, The University of Texas at Austin, Austin, TX, USA

Reihonna L. Frost Department of Psychology, Clark University, Worcester, MA, USA

Erica Frydenberg Melbourne Graduate School of Education, University of Melbourne, Melbourne, VIC, Australia

Sarah T. Furlong Illawarra Health and Medical Research Institute and Graduate Medicine, School of Medicine, University of Wollongong, Wollongong, NSW, Australia

Wendy C. Gamble Fun Science for Kids, Tucson, AZ, USA

Emily P. Garai Atlanta Psychological Services, Atlanta, GA, USA

Judy Garber Department of Psychology and Human Development, Vanderbilt University, Nashville, TN, USA

Rashmi Garg Psychology Department, Laurentian University, Sudbury, ON, Canada

N. Garnefski Department of Clinical, Health and Neuropsychology, Institute for Psychological Research, Leiden University, Leiden, The Netherlands

Stephen M. Gavazzi Human Sciences, The Ohio State University, Columbus, OH, USA

W. A. Gebhardt Department of Clinical, Health and Neuropsychology, Institute for Psychological Research, Leiden University, Leiden, The Netherlands

S. Geoffrey Severtson Department of Mental Health, Johns Hopkins Bloomberg School of Public Health, Baltimore, MD, USA

Western Psychiatric Institute and Clinic, University of Pittsburgh, Pittsburgh, PA, USA

Gary R. Germo Department of Human Services, California State University, Fullerton, CA, USA

Camille A. Gibson Department of Justice Studies, Prairie View A \& M University, Prairie View, TX, USA

Meghan M. Gillen Department of Psychology, The Pennsylvania State University, Abington, PA, USA 
Erin B. Godfrey Department of Applied Psychology, Steinhardt School of Culture, Education, and Human Development, New York University, New York, NY, USA

Trenette Clark Goings School of Social Work, University of North Carolina at Chapel Hill, Chappel Hill, NC, USA

Christian Gold GAMUT, Uni Research Health, Bergen, Norway

Abbie E. Goldberg Department of Psychology, Clark University, Worcester, MA, USA

Limor Goldner Graduate School of Creative Art Therapies, University of Haifa, Haifa, Israel

Asha Goldweber Department of Mental Health, Johns Hopkins Bloomberg School of Public Health, Baltimore, MD, USA

Haylie L. Gomez The University of Texas at Arlington, Arlington, TX, USA

Jennifer M. Reingle Gonzalez Department of Epidemiology, Human Genetics, and Environmental Sciences, University of Texas School of Public Health, Dallas, TX, USA

Marie Good Lifespan Development Psychology, Brock University, St. Catharines, ON, Canada

Patricia Goodson Department of Health and Kinesiology, Texas A\&M University, College Station, TX, USA

Crystal Gray Department of Counseling and Educational Development, University of North Carolina at Greensboro, Greensboro, NC, USA

Julie Ann Gray Rockville, MD, USA

Ellen Greenberger Department of Psychology and Social Behavior, School of Social Ecology, University of California - Irvine, Irvine, CA, USA

Kaylin M. Greene Department of Sociology and Anthropology, Montana State University, Bozeman, MT, USA

Patrick M. Grehan Derner Institute of Advanced Psychological Studies, Adelphi University, Garden City, NY, USA

Barbara Greybeck Department of Language, Literacy, and Special Populations, Sam Houston State University, Huntsville, TX, USA

Rachel L. Grover Department of Psychology, Loyola University Maryland, Baltimore, MD, USA

Nancy G. Guerra University of Delaware, Newark, DE, USA

Dave Gussak Florida State University, Tallahassee, FL, USA

Carl A. Gustavo Carlo Department of Psychology, University of NebraskaLincoln, Lincoln, NE, USA 
Sally M. Hage Division of Counseling Psychology, University at Albany, Albany, NY, USA

Rachel Haine-Schlagel Child and Adolescent Services Research Center, San Diego State University and Rady Children's Hospital, San Diego, CA, USA

William W. Hale III Research Centre Adolescent Development, Utrecht University, Utrecht, The Netherlands

Wayne D. Hall School of Population Health and Centre for Youth Substance Abuse Research, University of Queensland, Herston, QLD, Australia

Susan P. Hall School Psychology, Teachers College, Columbia University, New York, NY, USA

Kenneth A. Haller Saint Louis University, School of Medicine, St. Louis, MO, USA

Leslie F. Halpern Department of Psychology, University at Albany, State University of New York, Albany, NY, USA

Robert Halpern Erikson Institute, Chicago, IL, USA

Liat Hamama Renata Adler Memorial Research Center for Child Welfare and Protection, Bob Shapell School of Social Work, Tel-Aviv University, Tel Aviv, Israel

Phillip L. Hammack Department of Psychology, University of California, Santa Cruz, Santa Cruz, CA, USA

Christopher J. Hammond Johns Hopkins University School of Medicine, Baltimore, MD, USA

Yale University School of Medicine, New Haven, CT, USA

Petra Hampel Institute of Health, Nutrition, and Sport Sciences, EuropaUniversität Flensburg, Flensburg, Germany

Benjamin L. Hankin Department of Psychology, University of Illinois, Urbana-Champaign, CO, USA

Sarah Hansen Department of Curriculum and Instruction, University of Minnesota, Minneapolis, MN, USA

Gordon P. Harper Child/Adolescent Services, Massachusetts Department of Mental Health, Harvard Medical School, Boston, MA, USA

Daniel Hart Center for Children and Childhood Studies, Rutgers University, Camden, NJ, USA

John Hattie Melbourne Graduate School of Education, University of Melbourne, Melbourne, VIC, Australia

Ian Hay University of Tasmania, Launceston, TAS, Australia

M. Susan Heaney Saint Louis University, School of Medicine, St. Louis, MO, USA 
Sue Heath School of Social Sciences, University of Southampton, Southampton, UK

Martine Hébert Département de sexologie, Université du Québec à Montréal, Montréal, QC, Canada

Kathleen M. Heide Department of Criminology, University of South Florida, Tampa, FL, USA

Richard C. Henriksen Jr. Department of Counselor Education, Sam Houston State University, Huntsville, TX, USA

Lisa M. Henry-Reid Division of Adolescent Medicine, John H. Stroger, Jr. Hospital of Cook County, Chicago, IL, USA

Christopher Hensley Department of Criminal Justice, University of Tennessee at Chattanooga, Chattanooga, TN, USA

Amy L. Hequembourg Research Institute on Addictions, University at Buffalo, State University of New York, Buffalo, NY, USA

Beate Herpertz-Dahlmann University Clinics, Technical University Aachen, Aachen, Germany

Emily Hielscher Centre for Clinical Research, The University of Queensland, Herston, QLD, Australia

Queensland Centre for Mental Health Research, The Park, Wacol, QLD, Australia

School of Public Health, The University of Queensland, Brisbane, QLD, Australia

Charmaine K. Higa-McMillan Department of Psychology, University of Hawai'i at Hilo, Hilo, HI, USA

Patrick L. Hill Department of Psychology, Carleton University, Ottawa, ON, Canada

Aline Hitti Department of Psychology, University of San Francisco, San Francisco, CA, USA

Jun Sung Hong School of Social Work, Wayne State University, Detroit, MI, USA

Department of Social Welfare, Sungkyunkwan University, Seoul, South Korea

Lisa M. Hooper Department of Counseling and Human Development, University of Louisville, Louisville, KY, USA

Yang Hou Department of Human Development and Family Sciences, The University of Texas at Austin, Austin, TX, USA

Stephen Houghton Graduate School of Education, The University of Western Australia, Nedlands, WA, Australia

School of Psychological Sciences and Health, Strathclyde University, Strathclyde, Glasgow, UK 
Matthew O. Howard UNC School of Social Work, Tate-Turner-Kuralt Building, Chapel Hill, NC, USA

Julie Milligan Hughes Psychology Department, The College of New Jersey, Ewing, NJ, USA

Mary Elizabeth Hughes Department of Population, Family, and Reproductive Health, Johns Hopkins Bloomberg School of Public Health, Baltimore, MD, USA

Peter G. Hummel Erikson Institute of the Austen Riggs Center, Stockbridge, MA, USA

Justin F. Hummer Department of Psychology, University of Southern California, Los Angeles, CA, USA

Noelle M. Hurd University of Virginia, Charlottesville, VA, USA

Mary Huser Family Living Programs, University of Wisconsin-Extension, Madison, WI, USA

Mathilde Husky INSERM U1219, Université de Bordeaux, Institut Universitaire de France, Bordeaux, France

Elizabeth D. Hutchison School of Social Work, Virginia Commonwealth University, Reno, NV, USA

Virginia W. Huynh California State University, Northridge, CA, USA

A. Iachini College of Social Work, University of South Carolina, Columbia, SC, USA

Nicholas S. Ialongo Department of Mental Health, Johns Hopkins Center for Prevention and Early Intervention, Johns Hopkins Bloomberg School of Public Health, Baltimore, MD, USA

Priya Iyer The University of Texas at Arlington, Arlington, TX, USA

Linda A. Jackson Michigan State University, East Lansing, MI, USA

Anna Januszewicz Warsaw School of Social Sciences and Humanities, Warsaw, Poland

Ashley Jaramillo Department of Mental Health, Johns Hopkins Bloomberg School of Public Health, Baltimore, MD, USA

Wesley G. Jennings Department of Criminology, University of South Florida, Tampa, FL, USA

Alexander C. Jensen School of Family Life, Brigham Young University, Provo, UT, USA 
Lauri A. Jensen-Campbell The University of Texas at Arlington, Arlington, TX, USA

Cynthia R. Johnson Department of Pediatrics, Children's Hospital of Pittsburgh, University of Pittsburgh School of Medicine, Pittsburgh, PA, USA

David W. Johnson Department of Educational Psychology, University of Minnesota, Minneapolis, MN, USA

Jeffrey G. Johnson New York State Psychiatric Institute, New York, NY, USA

Department of Psychiatry, Columbia University College of Physicians and Surgeons, New York, NY, USA

Roger T. Johnson Department of Curriculum and Instruction, University of Minnesota, Minneapolis, MN, USA

Jacob Jones Department of Social and Behavioral Sciences, Colorado Mesa University, Grand Junction, CO, USA

Paul E. Jose Centre for Applied Cross Cultural Research, School of Psychology, Victoria University of Wellington, Wellington, New Zealand

Hayal Z. Kackar-Cam Department of Leadership, Educational Psychology and Foundations, Northern Illinois University, DeKalb, IL, USA

Riittakerttu Kaltiala-Heino Medical School, University of Tampere, Tampere, Finland

Department of Adolescent Psychiatry, Tampere University Hospital, Pitkäniemi, Finland

Praveen Kambam Psychiatry and Biobehaviorial Sciences, University of California, Los Angeles, Los Angeles, CA, USA

Nilamadhab Kar Wolverhampton City PCT, Corner Houser Resource Centre, Wolverhampton, UK

Joan Kaufman Johns Hopkins University School of Medicine, Baltimore, MD, USA

Center for Child and Family Traumatic Stress, Kennedy Krieger Institute, Baltimore, MD, USA

Lila Kazemian Department of Sociology, John Jay College of Criminal Justice, New York, NY, USA

Christopher A. Kearney Department of Psychology, University of Nevada, Las Vegas, Las Vegas, NV, USA

Michael S. Kelly School of Social Work, Loyola University Chicago, Chicago, IL, USA

Philip C. Kendall Child and Adolescent Anxiety Disorders Clinic, Temple University, Philadelphia, PA, USA 
Shannon R. Kenney Department of Psychiatry and Human Behavior, Alpert Medical School of Brown University, Providence, RI, USA

Patricia K. Kerig Department of Psychology, University of Utah, Salt Lake City, UT, USA

Lisa Kettler Trinity College Gawler Inc, Evanston South, SA, Australia The School of Psychology, The University of Adelaide, Adelaide, SA, Australia

Shereen Khan Department of Educational and Counselling Psychology, and Special Education, University of British Columbia, Vancouver, BC, Canada

Lisa Kiang Wake Forest University, Winston-Salem, NC, USA

Melanie Killen Department of Human Development and Quantitative Methodology, University of Maryland, College Park, MD, USA

Hyunsoo Kim Mandel School of Applied Social Sciences, Case Western Reserve University, Cleveland, OH, USA

Su Yeong Kim Department of Human Development and Family Sciences, The University of Texas at Austin, Austin, TX, USA

Beverly Kingston Adams County Youth Initiative, Thornton, CO, USA

Douglas Kirby ETR Associates, Scotts Valley, CA, USA

Teresa Kirchner Department of Personality, Assessment and Psychological Treatments, University of Barcelona, Barcelona, Spain

Stavros P. Kiriakidis Department of Preschool Education, University of Crete, Crete, Greece

Department of Educational and Social Policy, University of Macedonia, Athens, Greece

Miriam H. Kirmayer Department of Psychology, McGill University, Montreal, QC, Canada

Ben Kirshner School of Education, University of Colorado, Boulder, CO, USA

Robert M. Klassen Department of Education, Psychology in Education Research Centre, University of York, York, UK

Theo A. Klimstra Developmental Psychology, Tilburg University, Tilburg, The Netherlands

Christine W. Koth Adjunct Department of Mental Health, Johns Hopkins Bloomberg School of Public Health, Baltimore, MD, USA

Daniel S. Kreitzberg Department of Kinesiology and Health Education, University of Texas at Austin, Austin, TX, USA

Deanna Kuhn Teachers College, Columbia University, New York, NY, USA Joseph W. LaBrie Loyola Marymount University, Los Angeles, CA, USA 
Andrew Lac Psychology Department, University of Colorado at Colorado Springs, Colorado Springs, CO, USA

Deborah Laible Department of Psychology, Lehigh University, Bethlehem, PA, USA

Jodi Lane Department of Sociology and Criminology and Law, University of Florida, Gainesville, FL, USA

Rachel Langevin Département de sexologie, Université du Québec à Montréal, Montréal, QC, Canada

Jennifer E. Lansford Center for Child and Family Policy, Duke University, Durham, NC, USA

Melanie M. Lantz Division of Counseling Psychology, University at Albany, Albany, NY, USA

Daniel Lapsley Department of Psychology, University of Notre Dame, Notre Dame, IN, USA

Nicole Larson Division of Epidemiology and Community Health, School of Public Health, University of Minnesota, Minneapolis, MN, USA

Brett Laursen Florida Atlantic University, Fort Lauderdale, FL, USA

Campbell Leaper Department of Psychology, University of California, Santa Cruz, CA, USA

Seon-Young Lee Department of Education, College of Education, Seoul National University, Seoul, South Korea

Michael J. Leiber Department of Criminology, University of South Florida, Tampa, FL, USA

Martin Leichtman Responsive Centers for Psychology and Learning, Overland Park, KS, USA

Natasha Lekes Department of Psychology, McGill University, Montreal, QC, Canada

Serafín Lemos-Giráldez Department of Psychology, University of Oviedo, Oviedo, Spain

Christopher J. Lennings LSC Psychology and Charles Sturt University, World Square, Sydney, NSW, Australia

Michela Lenzi Department of Social and Developmental Psychology, University of Padova, Padova, Italy

Jared Lessard Department of Research, Planning, and Accreditation, Irvine Valley College, Irvine, CA, USA

Roger J. R. Levesque Indiana University, Bloomington, IN, USA

Theodore Lewis School of Learning, Cognition and Education, University of Trinidad and Tobago, Curepe/Valsayn, Trinidad and Tobago 
Carrie K. W. Li School of Criminal Justice, Michigan State University, East Lansing, MI, USA

Karen Liljequist Medical Center Libraries and Technologies, University of Rochester Medical Center, Rochester, NY, USA

Alex Lin University of California, Irvine, CA, USA

Sara M. Lindberg Population Health Institute, University of WisconsinMadison, Madison, WI, USA

Frank Lindblad Department of Child and Adolescent Psychiatry, Division of Neuroscience, Uppsala University, Uppsala, Sweden

Sally Lindsay Holland Bloorview Kids Rehabilitation Hospital, Bloorview Research Institute, University of Toronto, Toronto, ON, Canada

Melissa A. Lippold The School of Social Work, The University of North Carolina at Chapel Hill, Chapel Hill, NC, USA

Katherine Little Department of Psychology, University of Tennessee, Knoxville, TN, USA

Jennifer A. Livingston Research Institute on Addictions, University at Buffalo, State University of New York, Buffalo, NY, USA

John E. Lochman Department of Psychology, The University of Alabama, Tuscaloosa, AL, USA

Meghan K. Loeser Department of Human Development and Family Studies, Purdue University, West Lafayette, IN, USA

Bonita London Department of Psychology, Stony Brook University, Stony Brook, NY, USA

Alexandra Loukas Department of Kinesiology and Health Education, The University of Texas at Austin, Austin, TX, USA

Monica Luciana Department of Psychology and Center for Neurobehavioral Development, University of Minnesota, Minneapolis, MN, USA

Aleksandra Luszczynska University of Colorado at Colorado Springs, Colorado Springs, CO, USA

Warsaw School of Social Sciences and Humanities, Wroclaw, Poland

Heidi Lyons Department of Sociology, Anthropology, Social Work, and Criminal Justice, Oakland University, Rochester, MI, USA

Robert MacDonald School of Social Sciences and Law, University of Teesside, Middlesbrough, UK

Sherri MacKay Department of Psychiatry, University of Toronto, Toronto, ON, Canada

Duhita Mahatmya College of Education, University of Iowa, Iowa City, IA, USA 
Mildred M. Maldonado-Molina Department of Health Outcomes and Policy, College of Medicine, University of Florida, Gainesville, FL, USA

Christopher A. Mallett School of Social Work, Cleveland State University, Cleveland, OH, USA

John Maltby Positive Psychology Research Centre, St Peter Port, Guernsey

Valeria Manera CoBTek Laboratory, University of Nice Sophia Antipolis, Nice, France

Jennifer A. Manganello Department of Health Policy, Management and Behavior, School of Public Health, University at Albany, SUNY, Rensselaer, NY, USA

Wendy Manning Department of Sociology, Bowling Green State University, Bowling Green, OH, USA

Malka Margalit Constantiner School of Education, Tel-Aviv University, Ramat-Aviv, Israel

Peres Academic Center, Rehovot, Israel

Charlotte H. Markey Department of Psychology, Rutgers University, Camden, NJ, USA

Dorothy Markiewicz Department of Psychology, Brock University, St. Catharines, ON, Canada

Andrew J. Martin School of Education, University of New South Wales, Sydney, NSW, Australia

Jaime Martinez Division of Adolescent Medicine, John H. Stroger, Jr. Hospital of Cook County, Chicago, IL, USA

Silvia S. Martins Department of Mental Health, Johns Hopkins Bloomberg School of Public Health, Baltimore, MD, USA

Peter Marton Independent Practice, Mississauga, ON, Canada

Emma K. Massey Kidney Transplant Unit, Department of Internal Medicine, Erasmus Medical Center, Rotterdam, CA, The Netherlands

N. Tatiana Masters Alcohol and Drug Abuse Institute, University of Washington, Seattle, WA, USA

Camden Elliott Matherne Department of Psychiatry, University of North Carolina at Chapel Hill, Chapel Hill, NC, USA

Jennifer L. Matjasko Department of Human Development and Family Sciences, The University of Texas at Austin, Austin, TX, USA

M. Kyle Matsuba Psychology Department, Kwantlen Polytechnic University, Surrey, BC, Canada

Leifa Mayers Department of Psychology, University of California, Santa Cruz, Santa Cruz, CA, USA 
Brandy R. Maynard School of Social Work, College for Public Health and Social Justice, Saint Louis University, St. Louis, MO, USA

Shelly Sadek McCoy La Sierra University, Riverside, CA, USA

Patrick McCrystal Institute of Child Care Research, School of Sociology, Social Policy and Social Work, Queen's University, Belfast, UK

Kristina L. McDonald Department of Psychology, University of Alabama, Tuscaloosa, AL, USA

Katrina McFerran School of Music, University of Melbourne, Parkville, VIC, Australia

Jenifer K. McGuire Family Social Science, University of Minnesota, WA, USA

University of Minnesota, St. Paul, MN, USA

Laura G. McKee Georgia State University, Atlanta, GA, USA

Elizabeth N. McLaughlin Department of Psychology, Dalhousie University, Halifax, NS, Canada

Pediatric Health Psychology, IWK Health Centre, Halifax, NS, Canada

Kate C. McLean Department of Psychology, Western Washington University, Bellingham, WA, USA

Patricia McNamara School of Social Work and Social Policy, La Trobe University, Melbourne, Australia

Benjamin Meade Department of Justice Studies, James Madison University, Harrisonburg, VA, USA

Kristin Meany-Walen University of Northern Iowa, Cedar Falls, IA, USA

Maria Medvedeva Princeton Writing Program, Princeton University, Princeton, NJ, USA

Wim H. J. Meeus Developmental Psychology, Tilburg University, Tilburg, The Netherlands

Research Centre Adolescent Development, Utrecht University, Utrecht, The Netherlands

Chris Melde School of Criminal Justice, Michigan State University, East Lansing, MI, USA

Lisa J. Meltzer National Jewish Health, Denver, CO, USA

Marina M. Mendoza National Institute of Justice, Washington, DC, USA

Gustavo Mesch Department of Sociology and Anthropology, The Center for the Study of Society, University of Haifa, Haifa, Israel 
Amori Yee Mikami Department of Psychology, University of British Columbia, Vancouver, BC, Canada

Amy J. Mikolajewski Department of Psychiatry and Behavioral Sciences, Tulane University, New Orleans, LA, USA

Avidan Milevsky Department of Behavioral Sciences, Ariel University, Ariel, Israel

Carlin J. Miller Department of Psychology, University of Windsor, Windsor, ON, Canada

Kathleen E. Miller Research Institute on Addictions, University at Buffalo, Buffalo, NY, USA

Motohide Miyahara School of Physical Education, Sport and Exercise Sciences, University of Otago, Dunedin, New Zealand

Kristiann D. S. Miyamoto Department of Psychology, University of Hawai'i at Mānoa, Honolulu, HI, USA

Kristin Mmari Department of Population, Family, and Reproductive Health, Johns Hopkins Bloomberg School of Public Health, Baltimore, MD, USA

Kathryn Lynn Modecki Arizona State University, Tempe, AZ, USA

Crosby A. Modrowski Department of Psychology, University of Utah, Salt Lake City, UT, USA

Kristin L. Moilanen Department of Learning Sciences and Human Development, West Virginia University, Morgantown, WV, USA

Karen S. Mooney Psychology Department, University of Illinois at Springfield, Springfield, IL, USA

Meghan B. Moran Johns Hopkins Bloomberg School of Public Health, Baltimore, MD, USA

Robert J. Moretti Clinical Psychiatry and Behavioral Sciences, Northwestern University Feinberg School of Medicine, C.G. Jung Institute of Chicago, Chicago, IL, USA

Michele Morningstar Department of Psychology, McGill University, Montreal, QC, Canada

Sherill V. C. Morris-Francis Department of Criminal Justice, Mississippi Valley State University, Itta Bena, MS, USA

David Moshman Educational Psychology, University of Nebraska, Lincoln, NE, USA

Michaela M. Mozley Department of Psychology, University of Utah, Salt Lake City, UT, USA

Jennifer J. Muehlenkamp Department of Psychology, University of Wisconsin-Eau Claire, Eau Claire, WI, USA 
Charles W. Mueller Department of Psychology, University of Hawaii at Mānoa, Honolulu, HI, USA

Carrie F. Mulford National Institute of Justice, Washington, DC, USA

Maura M. Mulloy-Anderson Division of Child and Adolescent Psychiatry, Center for School Mental Health, University of Maryland School of Medicine, Baltimore, MD, USA

Kelly Lynn Mulvey Department of Educational Studies, University of South Carolina, Columbia, SC, USA

José Muñiz Department of Psychology, University of Oviedo, Oviedo, Spain Carlos III Health Institute, Research Centre in the Mental Health Network (CIBERSAM), Madrid, Spain

Michelle R. Munson Mandel School of Applied Social Sciences, Case Western Reserve University, Cleveland, OH, USA

Silver School of Social Work, New York University, New York, NY, USA

Tamera B. Murdock Department of Psychology, University of MissouriKansas City, Kansas City, MO, USA

Richelle Mychasiuk University of Calgary, Calgary, AL, Canada

Douglas W. Nangle Department of Psychology, University of Maine, Orono, ME, USA

Larry J. Nelson School of Family Life, Brigham Young University, Provo, UT, USA

Judith A. Nelson Department of Counselor Education, Sam Houston State University, Huntsville, TX, USA

Department of Educational Leadership and Counseling, Sam Houston State University, Huntsville, TX, USA

Dianne Neumark-Sztainer Division of Epidemiology and Community Health, School of Public Health, University of Minnesota, Minneapolis, MN, USA

Bic Ngo Department of Curriculum and Instruction, University of Minnesota, Minneapolis, MN, USA

Nicole Nicotera Graduate School of Social Work, University of Denver, Denver, CO, USA

Kei Nomaguchi Department of Sociology, Bowling Green State University, Bowling Green, OH, USA

Barry Nurcombe Centre for Clinical Research, The University of Queensland, Herston, QLD, Australia

James M. O'Neil Department of Educational Psychology, University of Connecticut, Storrs, CT, USA 
Benjamin M. Ogles College of Arts and Sciences, Ohio University, Athens, $\mathrm{OH}, \mathrm{USA}$

Vanessa G. Ohta Quantitative Methods in the Social Sciences Program (QMSS), Institute for Social and Economic Research and Policy (ISERP), Columbia University, New York, NY, USA

Paula Olszewski-Kubilius Center for Talent Development, School of Education and Social Policy, Northwestern University, Evanston, IL, USA

Janine V. Olthuis Department of Psychology, Dalhousie University, Halifax, NS, Canada

Trina E. Orimoto Department of Psychology, University of Hawai'i at Mānoa, Honolulu, HI, USA

Simone Orlowski Department of Psychiatry, School of Medicine, Flinders University, Adelaide, SA, Australia

Soraya Otero-Cuesta Psychiatry Outpatient Unit, Servei Valencia de Salut, Requena, Comunitat Valencia, Spain

Julie Owen School of Integrative Studies, George Mason University, Fairfax, VA, USA

Allison Owen-Anderson Child, Youth, and Family Program, Gender Identity Service, Centre for Addiction and Mental Health, Toronto, ON, Canada

Lee M. Pachter St. Christopher's Hospital for Children, Philadelphia, PA, USA

Drexel University College of Medicine, Philadelphia, PA, USA

Mercedes Paino Department of Psychology, University of Oviedo, Oviedo, Spain

Emma J. Palmer Department of Neuroscience, Psychology and Behaviour, University of Leicester, Leicester, UK

Keryn E. Pasch Department of Kinesiology and Health Education, University of Texas at Austin, Austin, TX, USA

Monisha Pasupathi Department of Psychology, University of Utah, Salt Lake City, UT, USA

Paola Pedrelli Department of Psychiatry, Massachusetts General Hospital, Boston, MA, USA

Harvard Medical School, Boston, MA, USA

Virginia Peisch Department of Psychological Science, Dewey Hall, University of Vermont, Burlington, VT, USA

Francheska Perepletchikova Child and Adolescent Psychiatry, Weil Cornell University School of Medicine, White Plains, NY, USA

Douglas Demaree Perkins Center for Community Studies, Peabody College, Vanderbilt University, Nashville, TN, USA 
Brian E. Perron School of Social Work, University of Michigan, Ann Arbor, MI, USA

Jochen Peter Amsterdam School of Communication Research, University of Amsterdam, Amsterdam, The Netherlands

Jean Sunde Peterson Department of Educational Studies, Purdue University, West Lafayette, IN, USA

Jennifer L. Petersen University of Wisconsin, Whitewater, WI, USA

Michele Peterson-Badali Department of Human Development and Applied Psychology, Ontario Institute for Studies in Education, University of Toronto, Toronto, ON, Canada

Hanno Petras American Institutes for Research, Washington, DC, USA

Vicky Phares Department of Psychology, University of South Florida, Tampa, FL, USA

Katy Phillips Psychosocial and Family Services, Great Ormond Street Hospital, London, UK

Jan P. Piek School of Psychology and Speech Pathology, Curtin University of Technology, Perth, WA, Australia

Bettina Piko Department of Behavioral Sciences, University of Szeged, Szeged, Hungary

Jonathan R. Pletcher Department of Pediatrics, Children's Hospital of Pittsburgh, University of Pittsburgh School of Medicine, Pittsburgh, PA, USA

Pallav Pokhrel Prevention and Control Program, Cancer Research Center of Hawaii, University of Hawaii, Honolulu, HI, USA

Koen Ponnet Department of Communication Studies, Ghent University, Ghent, Belgium

Department of Communication Studies, University of Antwerp, Antwerp, Belgium

Higher Institute for Family Sciences, Odisee, Brussels, Belgium

Mick Power Section of Clinical and Health Psychology, University of Edinburgh, Medical School, Edinburgh, UK

Heather A. Priess-Groben Simpson College, Indianola, IA, USA

Carmel Proctor Positive Psychology Research Centre, St Peter Port, Guernsey

Rosemary Purcell Orygen, The National Centre of Excellence in Youth Mental Health and Centre for Youth Mental Health, The University of Melbourne, Parkville, VIC, Australia

Patrick D. Quinn Department of Psychology, The University of Texas at Austin, Austin, TX, USA 
Quinten A. W. Raaijmakers Research Centre Adolescent Development, Utrecht University, Utrecht, The Netherlands

Stacey P. Raj Department of Psychology, Miami University, Oxford, OH, USA

Katrina Ramsey Department of Psychology, University of Hawai'i at Hilo, Hilo, HI, USA

Kendra Ramsay Department of Psychology, Carleton University, Ottawa, ON, Canada

Lisa M. Ranzenhofer Weight Control and Diabetes Research Center, Alpert Medical School of Brown University/The Miriam Hospital, Providence, RI, USA

Jason R. D. Rarick Department of Applied Psychology, Steinhardt School of Culture, Education, and Human Development, New York University, New York, NY, USA

Kaylin Ratner Department of Human Development, Cornell University, Ithaca, NY, USA

Vaishali V. Raval Department of Psychology, Miami University, Oxford, $\mathrm{OH}$, USA

Richard E. Redding Crean College of Health and Behavioral Sciences; College of Educational Studies; and Fowler School of Law, Chapman University, Orange, CA, USA

Paula Redpath Department of Psychiatry, School of Medicine, Flinders University, Adelaide, SA, Australia

Sara Reeves Department of Health and Kinesiology, Texas A\&M University, College Station, TX, USA

Kevin S. Reimer School of Education, University of California, Irvine, CA, USA

Felice Resnik Department of Educational Psychology, University of Wisconsin-Madison, Madison, WI, USA

Heathe H. Luz McNaughton Reyes Gillings School of Global Public Health, University of North Carolina at Chapel Hill, Chapel Hill, NC, USA

J. Reynolds College of Social Work, University of South Carolina, Columbia, SC, USA

Rhonda A. Richardson Human Development and Family Studies, Kent State University, Kent, $\mathrm{OH}$, USA

Daniela Rigoli School of Psychology and Speech Pathology, Curtin University of Technology, Perth, WA, Australia

A. Riley Girls on the Run International, Charlotte, OH, USA 
Donald Rimer International Authority on Ritual Crime and the Occult, Public Information Office, Virginia Gang Investigators Association, Chesapeake, VA, USA

Erin E. Ring Division of Counseling Psychology, University at Albany, Albany, NY, USA

Ken Ripperger-Suhler Department of Psychological, Health, and Learning Sciences, The University of Houston, Houston, TX, USA

Emily Rischall Roosevelt University, Chicago, IL, USA

Carrie W. Rishel Division of Social Work, West Virginia University, Morgantown, WV, USA

Michelle S. Rivera E.P. Bradley Hospital and Brown University Medical School, Providence, RI, USA

Anthony James Roberson Capstone College of Nursing, The University of Alabama, Tuscaloosa, AL, USA

Janice M. Roberts Private Practice, Sydney, NSW, Australia

Troy A. Robison Psychology Department, Ohio University, Athens, OH, USA

Rachael D. Robnett University of Nevada at Las Vegas, Las Vegas, NV, USA

Kara Anne E. Rodenhizer-Stämpfli Department of Psychology, University of New Hampshire, Durham, NH, USA

Dominique E. Roe-Sepowitz Office of Forensic Social Work, School of Social Work, Arizona State University, Phoenix, AZ, USA

Ariz Rojas Department of Psychology, University of South Florida, Tampa, FL, USA

Daniel Romer Annenberg Public Policy Centre, University of Pennsylvania, Philadelphia, Pennsylvania, PA, USA

Andrea J. Romero Family Studies and Human Development, Mexican American and Raza Studies, University of Arizona, Tucson, AZ, USA

Tammie Ronen Renata Adler Memorial Research Center for Child Welfare and Protection, Bob Shapell School of Social Work, Tel-Aviv University, Tel Aviv, Israel

Rachel Rose Department of Psychology, Hofstra University, Hempstead, NY, USA

Janet E. Rosenbaum Department of Epidemiology and Biostatistics, School of Public Health, SUNY Downstate Medical Center, Brooklyn, NY, USA 
Cary J. Roseth Department of Counseling, Educational Psychology, and Special Education, Michigan State University, East Lansing, MI, USA

Edward D. Rossini Department of Psychology, Roosevelt University, Schaumburg, IL, USA

Ethan Rothstein Department of Psychology, University of Maine, Orono, ME, USA

Kenneth H. Rubin University of Maryland, College Park, MD, USA

Vladislav Ruchkin Department of Child and Adolescent Psychiatry, Division of Neuroscience, Uppsala University, Uppsala, Sweden

Child Study Center, Yale University Medical School, New Haven, CT, USA

Säter Forensic Psychiatric Clinic, Säter, Sweden

Martin D. Ruck Developmental Psychology, The Graduate Center, City University of New York, New York, NY, USA

Kevin C. Runions Telethon Kids Institute, Subiaco, WA, Australia

Keith C. Russell College of Humanities and Social Sciences, Western Washington University, Bellingham, WA, USA

Carolyn M. Rutledge School of Nursing, Old Dominion University, Norfolk, VA, USA

Erin M. Ruttle York University, Toronto, ON, Canada

Suvi H. Saarikallio Department of Music, Art and Culture Studies, University of Jyväskylä, Jyväskylä, Finland

Olle Jane Z. Sahler Division of Adolescent Medicine, Golisano Children's Hospital, University of Rochester School of Medicine and Dentistry, Rochester, NY, USA

Randall T. Salekin Disruptive Behavior Clinic, Department of Psychology, Center for the Prevention of Youth Behavior Problems, The University of Alabama, Tuscaloosa, AL, USA

Heidi Sallee Saint Louis University, School of Medicine, St. Louis, MO, USA

Susan Saltzburg College of Social Work, Ohio State University, Columbus, $\mathrm{OH}, \mathrm{USA}$

Suzanne Salzinger Department of Child and Adolescent Psychiatry, New York State Psychiatric Institute and Columbia University, New York, NY, USA

María Luisa Sánchez-Bernardos Department of Personality, Assessment, and Clinical Psychology, Faculty of Psychology, Complutense University of Madrid, Somosaguas, Pozuelo de Alarcón, Madrid, Spain

Almudena Sanchez-Bou Department of Psychiatry and Psychology, Hospital Universitario Marques de Valdecilla, School of Medicine, Cantabria University, Santander, Cantabria, Spain 
Catherine DeCarlo Santiago Department of Psychology, Loyola University Chicago, Chicago, IL, USA

Massimo Santinello Department of Social and Developmental Psychology, University of Padova, Padova, Italy

Joanne Savage American University, Washington, DC, USA

Peter C. Scales Search Institute, Manchester, MO, USA

Cindy M. Schaeffer Child and Adolescent Psychiatry, University of Maryland Department of Psychiatry, Baltimore, MD, USA

Miri Scharf Department of Counseling and Human Development, University of Haifa, Haifa, Israel

Edward J. Schauer Prairie View A\&M University, Prairie View, TX, USA

Wolff Schlotz School of Psychology, University of Southampton, Southampton, UK

Fred Schmidt Children's Centre Thunder Bay and Lakehead University, Thunder Bay, ON, Canada

Erin N. Schoenfelder Department of Psychology, Arizona State University, Phoenix, AZ, USA

David A. Scott Department of Counselor Education, Clemson University, Clemson, SC, USA

James G. Scott Centre for Clinical Research, The University of Queensland, Herston, QLD, Australia

Metro North Mental Health, The Royal Brisbane and Women's Hospital, Herston, QLD, Australia

Queensland Centre for Mental Health Research, The Park, Wacol, QLD, Australia

Lionel D. Scott Georgia State University, Atlanta, GA, USA

Eleanor K. Seaton T. Denny Sanford School of Social and Family Dynamics, Arizona State University, Tempe, AZ, USA

Catherine Sebastian UCL Department of Clinical, Educational and Health Psychology, Division of Psychology and Language Science, London, UK

Rachel Seginer University of Haifa Mount Carmel, Haifa, Israel

Emek Yezreel College, Nazareth, Israel

Cara A. Settipani Child and Adolescent Anxiety Disorders Clinic, Temple University, Philadelphia, PA, USA

David E. Shaenfield Teachers College, Columbia University, New York, NY, USA

Lisa Shank Department of Medical and Clinical Psychology, Uniformed Services University of the Health Sciences, Bethesda, MD, USA 
Benjamin G. Shapero Department of Psychiatry, Massachusetts General Hospital, Boston, MA, USA

Harvard Medical School, Boston, MA, USA

Jennifer D. Shapka Department of Educational and Counselling Psychology, and Special Education, University of British Columbia, Vancouver, BC, Canada

K. S. Shattuck Department of Psychology, Wayne State University, Detroit, MI, USA

David J. Shernoff Center for Mathematics, Science, and Computer Education, Rutgers University, Piscataway, NJ, USA

Department of School Psychology, Rutgers University, Piscataway, NJ, USA

Dana M. Sheshko Department of Psychology, University of Ottawa, Ottawa, Canada

Tracy Shildrick Youth Research Group, University of Teesside, Middlesbrough, UK

Del Siegle Educational Psychology Department, University of Connecticut, Storrs, CT, USA

Susana Sierra-Baigrie Department of Psychology, University of Oviedo, Oviedo, Spain

Sarah K. Sifers Department of Psychology, Minnesota State University, Mankato, MN, USA

Sandra D. Simpkins University of California, Irvine, CA, USA

David A. Sleet Centers for Disease Control and Prevention, National Center for Injury Prevention and Control, Atlanta, GA, USA

Stephen A. Small Department of Human Development and Family Studies, University of Wisconsin-Madison/Extension, Madison, WI, USA

Sven Smith Stetson University, DeLand, FL, USA

Sondra Smith-Adcock School of Human Development and Organizational Studies in Education, University of Florida, Gainesville, FL, USA

Paul R. Smokowski School of Social Welfare, University of Kansas, Lawrence, $\mathrm{KS}, \mathrm{USA}$

Bonnie J. Solomon University of Illinois at Chicago, Chicago, IL, USA

Jason S. Spendelow Private Practitioner, Hamilton, New Zealand

Henri-Lee Stalk Department of Psychology, University of Hawai'i at Mānoa, Honolulu, HI, USA

Elizabeth Stearns Department of Sociology, University of North Carolina at Charlotte, Charlotte, NC, USA 
Patrizia Steca Dipartimento di Psicologia, Università degli Studi di MilanoBicocca, Milano, Italy

Michael F. Steger Department of Psychology, Colorado State University, Fort Collins, CO, USA

Benjamin Steiner School of Criminology and Criminal Justice, University of Nebraska, Omaha, NE, USA

Sherry H. Stewart Departments of Psychology, Psychiatry, and Community Health and Epidemiology, Dalhousie University, Halifax, NS, Canada

Paul C. Stey Brown Center for Biomedical Informatics, Brown University, Providence, RI, USA

Wendy P. Stickle University of Maryland, College Park, MD, USA

Joachim Stoeber School of Psychology, University of Kent, Canterbury, Kent, UK

Carla L. Storr Department of Mental Health, Johns Hopkins Bloomberg School of Public Health, Baltimore, MD, USA

Department of Family and Community Health, University of Maryland School of Nursing, Baltimore, MD, USA

Mary Story Division of Epidemiology and Community Health, School of Public Health, University of Minnesota, Minneapolis, MN, USA

Anna D. Strati Glenbard Township High School District 87, Glen Ellyn, IL, USA

Jeffrey R. Strawn Department of Pediatrics, Division of Child and Adolescent Psychiatry, Cincinnati Children's Hospital Medical Center, Cincinnati, $\mathrm{OH}$, USA

Brandyn M. Street Department of Psychology and Human Development, Vanderbilt University, Nashville, TN, USA

Catherine B. Stroud Department of Psychology, Williams College, Williamstown, MA, USA

May Sudhinaraset Department of Population, Family, and Reproductive Health, Johns Hopkins Bloomberg School of Public Health, Baltimore, MD, USA

Christopher Sullivan School of Criminal Justice, University of Cincinnati, Cincinnati, OH, USA

S. R. Sumter Amsterdam School of Communication Research (ASCoR), University of Amsterdam, Amsterdam, The Netherlands

Steve Sussman Institute for Health Promotion and Disease Prevention Research, University of Southern California, Los Angeles, CA, USA

Hannah S. Szlyk School of Social Work, University of Texas, Austin, TX, USA 
Sharon Sznitman School of Public Health, University of Haifa, Haifa, Israel

David E. Szwedo Department of Psychology, James Madison University, Harrisonburg, VA, USA

Julie Y. Takishima-Lacasa Department of Psychology, University of Hawai'i at Manoa, Honolulu, HI, USA

Suzanne E. Tallichet Department of Sociology, Social Work, and Criminology, Morehead State University, Morehead, KY, USA

Jennifer L. Tanner Rutgers University, Institute for Health, Health Care Policy and Aging Research, Mountain Lakes, NJ, USA

Marian Tanofsky-Kraff Department of Medical and Clinical Psychology, Uniformed Services University of the Health Sciences, Bethesda, MD, USA

Eugene Tartakovsky The Bob Shapell School of Social Work, Tel Aviv University, Tel Aviv, Israel

Jeanette Taylor Department of Psychology, Florida State University, Tallahassee, FL, USA

Chinmayi Tengsche University of Illinois, Urbana-Champaign, IL, USA

Cydney J. Terreri Psychology Department, Fordham University, Bronx, NY, USA

Maria Testa Research Institute on Addictions, University at Buffalo, State University of New York, Buffalo, NY, USA

Sally A. Theran Psychology Department, Wellesley College, Wellesley, MA, USA

Jocelyn H. Thomas Sleep Center, The Children's Hospital of Philadelphia, Philadelphia, PA, USA

Stuart D. M. Thomas Centre for Applied Social Research and Justice and Legal Studies, School of Global, Urban and Social Studies, RMIT University, Melbourne, Australia

Christopher Thompson Department of Psychiatry and Behavioral Sciences, David Geffen School of Medicine at UCLA, University of California, Los Angeles, CA, USA

Gregory Thompson Counseling Department, John Jay College of Criminal Justice, New York, NY, USA

Morgan J. Thompson Psychology Department, The College of William and Mary, Williamsburg, VA, USA

Shira Tibon-Czopp Goldsmiths, University of London, London, UK

Lauree C. Tilton-Weaver Örebro University, Örebro, Sweden

Olga Tingstedt Department of Child and Adolescent Psychiatry, Division of Neuroscience, Uppsala University, Uppsala, Sweden 
Deborah L. Tolman Hunter College and The Graduate Center, Hunter College, City University of New York, New York, NY, USA

Peter F. Toscano Department of Psychology, Assumption College, Worcester, MA, USA

Caleb E. Trentham Department of Criminal Justice, University of Tennessee at Chattanooga, Chattanooga, TN, USA

Emilee H. Turner Department of Psychology, University of Hawaii at Mānoa, Honolulu, HI, USA

Kylan S. Turner Department of Instruction and Learning, University of Pittsburgh School of Education, Pittsburgh, PA, USA

Silvy Un Department of Curriculum and Instruction, University of Minnesota, Minneapolis, MN, USA

Christopher J. Urban Department of Psychology, Stony Brook University, Stony Brook, NY, USA

Patti M. Valkenburg Amsterdam School of Communication Research, University of Amsterdam, Amsterdam, The Netherlands

Marloes P. A. Van Dijk Utrecht University, Utrecht, The Netherlands

Mitch van Geel Department of Education and Child Studies, Rommert Casimir Institute, Leiden University, Leiden, The Netherlands

Michael G. Vaughn School of Social Work, Division of Epidemiology, School of Public Health, Department of Public Policy Studies, Saint Louis University, St. Louis, MO, USA

Paul Vedder Department of Education and Child Studies, Rommert Casimir Institute, Leiden University, Leiden, The Netherlands

Elizabeth Velilla City University of New York, New York, NY, USA

Carol Veneziano Department of Criminal Justice, Southeast Missouri State University, Cape Girardeau, MO, USA

Anthony Venning Department of Psychiatry, School of Medicine, Flinders University, Adelaide, SA, Australia

Christina L. Voonasis Southern Connecticut State University, New Haven, CT, USA

R. Wade-Mdivanian College of Social Work, Ohio State University, Columbus, OH, USA

Martha E. Wadsworth The Pennsylvania State University, University Park, PA, USA

Sara M. Walsh Department of Criminology and Criminal Justice, Indiana University Southeast, New Albany, IN, USA 
Eric R. Walsh-Buhi Division of Health Promotion and Behavioral Science, Graduate School of Public Health, San Diego State University, San Diego, CA, USA

Anna Ward Teachers College, Columbia University, New York, NY, USA

Ashley K. Ward Ryerson University, Toronto, ON, Canada

M. Nicole Warehime Department of Sociology, Gerontology and Substance Abuse Studies, University of Central Oklahoma, Edmond, OK, USA

Tyreasa Washington Department of Social Work, University of North Carolina at Greensboro, Greensboro, NC, USA

Laura E. Watkins Department of Psychiatry, Yale School of Medicine, VA Connecticut Healthcare System, National Center for PTSD-Clinical Neuroscience Division, West Haven, CT, USA

Margo C. Watt Department of Psychology, Saint Francis Xavier University, Antigonish, NS, Canada

Michael Weaver Department of Psychiatry and Behavioral Sciences, University of Texas McGovern Medical School, Houston, TX, USA

Scott Weber Nursing and Public Health, University of Pittsburgh, Pittsburgh, PA, USA

Carl F. Weems Department of Human Development and Family Studies, Iowa State University, Ames, IA, USA

Michael L. Wehmeyer Department of Special Education and Beach Center on Disability, University of Kansas, Lawrence, KS, USA

G. Weisfeld Department of Psychology, Wayne State University, Detroit, MI, USA

Christopher Weiss Quantitative Methods in the Social Sciences Program (QMSS), Institute for Social and Economic Research and Policy (ISERP), Columbia University, New York, NY, USA

M. Weist Division of Child and Adolescent Psychiatry, Center for School Mental Health, University of Maryland School of Medicine, Baltimore, MD, USA

Karen C. Wells Department of Psychiatry and Behavioral Sciences, Duke University Medical Center, Durham, NC, USA

Deborah Welsh Department of Psychology, University of Tennessee, Knoxville, TN, USA

Kathryn Wentzel Department of Human Development, University of Maryland, College Park, MD, USA

Julie Wershler Department of Psychology, University of New Brunswick, Fredericton, Fredericton, NB, Canada 
P. M. Westenberg Developmental and Educational Psychology Unit, Leiden University, Leiden, The Netherlands

Elizabeth M. Wheaton Equip the Saints (NPO), Prairie View, TX, USA

Elizabeth M. A. Wheeler Central State Hospital, Petersburg, VA, USA

Rob White School of Sociology and Social Work, University of Tasmania, Hobart, TAS, Australia

Stuart F. White Boys Town National Research Hospital, Omaha, NE, USA

Taryn White Saint Louis University, School of Medicine, St. Louis, MO, USA

Shawn D. Whiteman Department of Human Development and Family Studies, Purdue University, West Lafayette, IN, USA

Daniel P. Wilkie Department of Psychology, University of Hawai'i at Mānoa, Honolulu, HI, USA

Dionne D. Williams National Center for Injury Prevention and Control, Centers for Disease Control and Prevention, Atlanta, GA, USA

Ariel A. Williamson Sleep Center, The Children's Hospital of Philadelphia, Philadelphia, PA, USA

Department of Psychological and Brain Sciences, University of Delaware, Newark, DE, USA

Teena Willoughby Lifespan Development Psychology, Brock University, St. Catharines, ON, Canada

Anne Wilson Paramedics / School of Medicine, Flinders University, The University of Adelaide, Adelaide, SA, Australia

Coralie J. Wilson Illawarra Health and Medical Research Institute and Graduate Medicine, School of Medicine, University of Wollongong, Wollongong, NSW, Australia

Kelly L. Wilson Department of Health and Kinesiology, Texas A\&M University, College Station, TX, USA

Ken C. Winters Winters Consulting Group, Falcon Heights, MN, USA

Audrey Wittrup University of Virginia, Charlottesville, VA, USA

Liesbeth Woertman Department of Clinical and Health Psychology, Utrecht University, Utrecht, The Netherlands

LaToya L. Wolfe Prairie View A\&M University, Prairie View, TX, USA

Brian C. Wolff Wolff Child Psychology, Denver, CO, USA

Marc Woodbury-Smith Departments of Psychiatry and Behavioral Neuroscience and Pediatrics, McMaster University, Hamilton, ON, Canada

Douglas W. Woods Department of Psychology, University of WisconsinMilwaukee, Milwaukee, WI, USA 
Jane E. Workman School of Architecture, Fashion Design and Merchandising Program, Southern Illinois University, Carbondale, IL, USA

Tess Yanisch Department of Applied Psychology, Steinhardt School of Culture, Education, and Human Development, New York University, New York, NY, USA

Tovah Yanover Hamilton, ON, Canada

David Yeager Stanford University, Palo Alto, CA, USA

Tiffany Yip Department of Psychology, Fordham University, Bronx, NY, USA

Susan Yoon The College of Social Work, The Ohio State University, Columbus, OH, USA

Jeong Jin Yu Department of Psychology, Umeå University, Umeå, Sweden

Susan M. Yussman Division of Adolescent Medicine, Golisano Children's Hospital, University of Rochester School of Medicine and Dentistry, Rochester, NY, USA

Anders Zachrisson Department of Psychology, University of Oslo, Oslo, Norway

Byron L. Zamboanga Department of Psychology, Smith College, Northampton, MA, USA

Debra H. Zand Saint Louis University, School of Medicine, St. Louis, MO, USA

Shepherd Zeldin School of Human Ecology, University of Wisconsin, Madison, WI, USA

Lening Zhang Department of Sociology and Criminal Justice, Saint Francis University, Loretto, PA, USA

Karen Zilberstein Smith College School for Social Work, Northampton, MA, USA

Melanie J. Zimmer-Gembeck Psychological Health Research Unit, School of Psychology and Griffith Health Institute, Gold Coast, QLD, Australia

Marc A. Zimmerman Department of Psychology, University of Michigan, Ann Arbor, MI, USA

Kenneth J. Zucker Child, Youth, and Family Program, Gender Identity Service, Centre for Addiction and Mental Health, Toronto, ON, Canada 